\title{
The first description of eggs in the male reproductive system of Physaloptera bispiculata (Nematoda: Spiruroidaea)
}

\author{
A. Oliveira-Menezes ${ }^{1 *}$, A. Lanfredi-Rangel ${ }^{2}$ and R.M. Lanfredi ${ }^{1}$ \\ ${ }^{1}$ Laboratório de Biologia de Helmintos Otto Wucherer, Instituto de \\ Biofísica Carlos Chagas Filho, Universidade Federal do Rio de Janeiro, \\ Centro de Ciências da Saúde, Av. Carlos Chagas Filho, s/n Bloco G, \\ CEP 21949-902 Rio de Janeiro, RJ, Brazil: ${ }^{2}$ Laboratório de Biologia de \\ Protozoários e Unidade de Microscopia Eletrônica, Centro de Pesquisa \\ Gonçalo Muniz, Fundação Oswaldo Cruz, Rua Waldemar Falcão, 121, \\ Candeal, Salvador, Bahia CEP 40296-710, Brazil
}

(Accepted 26 June 2010; First Published Online 26 July 2010)

\begin{abstract}
Physaloptera bispiculata (Nematoda: Spiruroidaea) is a parasite of Nectomys squamipes (Rodentia: Cricetidae), a water rat that only occurs in Brazil. Naturally infected rodents were captured in the municipality of Rio Bonito, Rio de Janeiro, Brazil. Adult P. bispiculata worms were collected, prepared and analysed by light and scanning electron microscopy. Under scanning electron microscopy, several eggs were seen glued by cement to the cloacal aperture. Light microscopy revealed that some male worms had an uncountable number of embryonated eggs in the ejaculatory duct, cloaca and also in the posterior portion of the intestine. The probable explanation is that the eggs developing in the female uterus are pumped by the female or sucked by the male to the cloacal opening and from this point to the intestine and ejaculatory duct. The male probably does not have the ability to expel the eggs and for this reason a large number were found in these organs. On the other hand, this could be an important adaptation for the parasite, i.e. male worms expelled by the host can carry a large number of eggs and spread them to intermediate hosts when ingested by these hosts. As far as we know this is the first record of a physalopterid nematode harbouring eggs in the cloacal region, ejaculatory duct or intestine.
\end{abstract}

\section{Introduction}

The spirurid nematodes, in the adult stage, are obligatory parasites of vertebrates and require one or more intermediate arthropod hosts (Stunkard, 1953). Insects serve as the intermediate host of species of the genus Physaloptera Rudolphi, 1819 (Gray \& Anderson, 1982), while reptiles and amphibians serve as paratenic hosts (Widmer, 1970). Nematodes of the Physaloptera

*Fax: + 55 (21) 2280-8193

E-mail: alek@biof.ufrj.br genus have been reported as parasites of amphibians, reptiles, birds and mammals, mainly in the stomach but sometimes also in the small intestine (Ortlepp, 1922, 1937).

Physaloptera bispiculata Vaz \& Pereira, 1935 (Spiruridae: Nematoda) is a parasite of Nectomys squamipes Brants, 1827 (Rodentia: Cricetidae), a water rat that only occurs in Brazil. Two studies report a high prevalence of physalopterid species in $N$. squamipes, probably causing similar lesions as those described for Turgida turgida (Nettles et al., 1975; Alden, 1995), since they were also found attached to the stomach wall. The P. bispiculata species was re-evaluated by Mafra \& Lanfredi (1998) based on morphometric and 
morphological data such as lips, papillae, teeth, amphids, and number and arrangement of the caudal papillae.

Nematode reproduction is usually sexual. Males are usually smaller than females (often much smaller) and often have a characteristically bent tail to hold the female for copulation. During copulation, one or more chitinized spicules move out of the cloaca and are inserted into the female's genital pore. Amoeboid sperm then crawl along the spicule into the female worm. Nematode sperm cells are thought to be the only eukaryotic cells without globular protein. Following fecundation, the female produces eggs, which can be embryonated or unembryonated when passed by the female, in the latter case meaning the fertilized eggs cannot develop (Blaxter et al., 1998).

\section{Materials and methods}

Naturally infected rodents were captured in the municipality of Rio Bonito in Rio de Janeiro state, Brazil. The abdominal and thoracic cavities were opened and the organs were placed separately in Petri dishes, kept in physiological saline and dissected under a stereomicroscope to obtain the helminths. Physaloptera bispiculata was collected from the stomach. Worms were washed twice in saline to remove tissue debris and fixed in $3 \mathrm{ml}$ glacial acetic acid, $7 \mathrm{ml}$ of $37 \%$ formaldehyde and $90 \mathrm{ml}$ of $70 \%$ ethanol (AFA) at $60^{\circ} \mathrm{C}$ and maintained in the same solution. For light microscopy, the nematodes were clarified in phenol $80 \%$ (70\% ethanol and phenolic acid) and mounted on temporary slides. Morphological analyses were made using differential interferential contrast (DIC) microscopy and the images were captured with an Olympus DP-12 digital camera coupled to an Olympus BX-51 light microscope. For scanning electron microscopy, the worms were washed in $0.1 \mathrm{M}$ cacodylate buffer, pH 7.2, postfixed in $1 \% \mathrm{OsO}_{4}$ and $0.8 \% \mathrm{~K}_{3} \mathrm{Fe}(\mathrm{CN})_{6}$, dehydrated in graded ethanol (30-100\%) for $2 \mathrm{~h}$, criticalpoint dried in $\mathrm{CO}_{2}$, sputter-coated with gold and examined under a JEOL JSM 5310 scanning electron microscope at $15 \mathrm{kV}$. The procedure adopted in this work was approved by the animal research committee of the Instituto de Biofísica Carlos Chagas Filho, UFRJ.
Voucher specimens were deposited at the Instituto Biológico de São Paulo (numbers 1583 A and B, one male and one female, respectively) and at the Natural History Museum, London (numbers 1997.2.3.5-7). The remaining specimens are in the Laboratório de Biologia de Helmintos Otto Wucherer collection.

\section{Results and discussion}

Nematodes were collected from the stomach, where they were usually firmly attached to the stomach wall. The morphology of the anterior end in both sexes shows two large lateral simple pseudolips, delimiting the cephalic end from the body and provided with papillae; a cuticle forming a cephalic collaret; and deirids located anterior to the nerve ring. The pattern of the male caudal region and the cloacal papillae arrangement, observed by light microscopy, allowed the specimens to be identified as Physaloptera bispiculata Vaz \& Pereira, 1935. Eleven $N$. squamipes were parasitized by $P$. bispiculata, with a total of 45 nematodes ( 40 adults and 5 juveniles; 33 females and 12 males).

Scanning electron microscopy of the posterior end of the male $P$. bispiculata worms showed the morphological features described by Mafra \& Lanfredi (1998). Some worms had an adhesive secretion, produced by the prostate glands, covering the ventral region, with some eggs adhering to the cloacal opening (fig. 1a).

The male ejaculatory duct is dorsally situated to the digestive tract and located at the rear portion of the body (fig. 1b). This structure is elongated and piriform, with its thickest portion located away from the cloaca (fig. 1b). The intestine, ejaculatory duct and pouch containing a pair of spicules open at the cloaca (fig. 2a).

Observations of male $P$. bispiculata worms by light microscopy revealed nine male worms containing embryonated eggs in the cloaca (fig. 1b), ejaculatory duct (fig. 2a and b) and rear portion of the intestine (fig. 2b). The number of eggs ranged from only a few to an uncountable number. This is an intriguing feature. Our suggestion is that the muscular contractions of the female associated with the back-and-forth movement of the spicules in the vagina and the body contraction of the
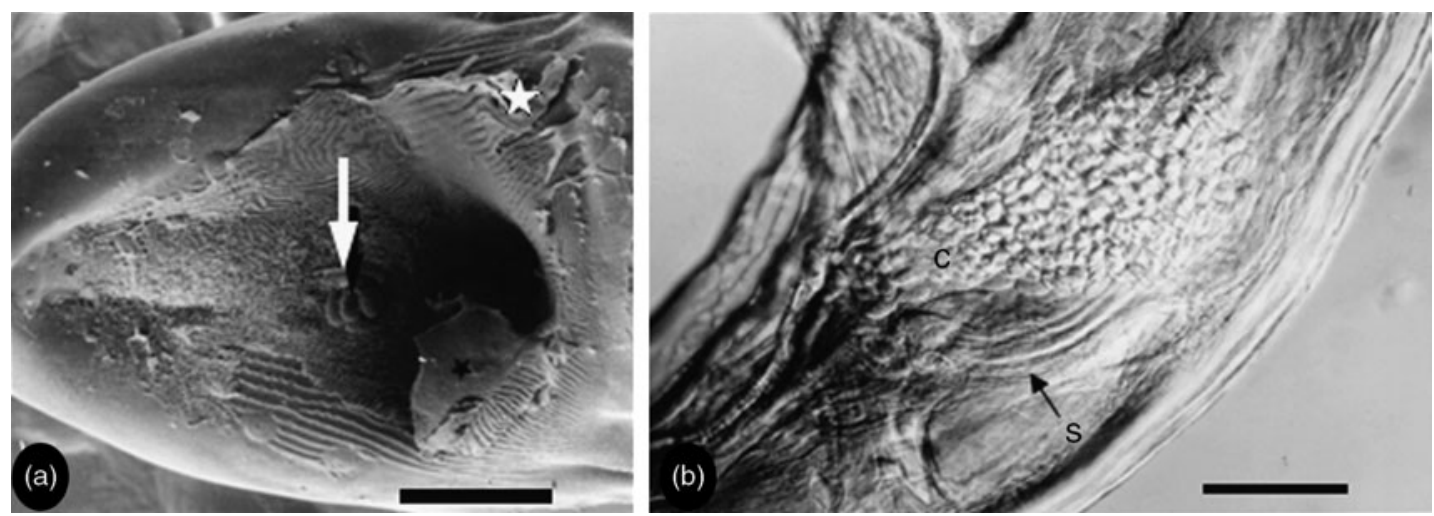

Fig. 1. Physaloptera bispiculata male. (a) Scanning electron microscopy showing the ventral side of the posterior end covered by cement (star) and the cloacal opening with eggs adhered to it (arrow) (scale bar $200 \mu \mathrm{m}$ ). (b) Light microscopy of cloacal region (C) full of eggs, and spicule (S) (scale bar $100 \mu \mathrm{m}$ ). 

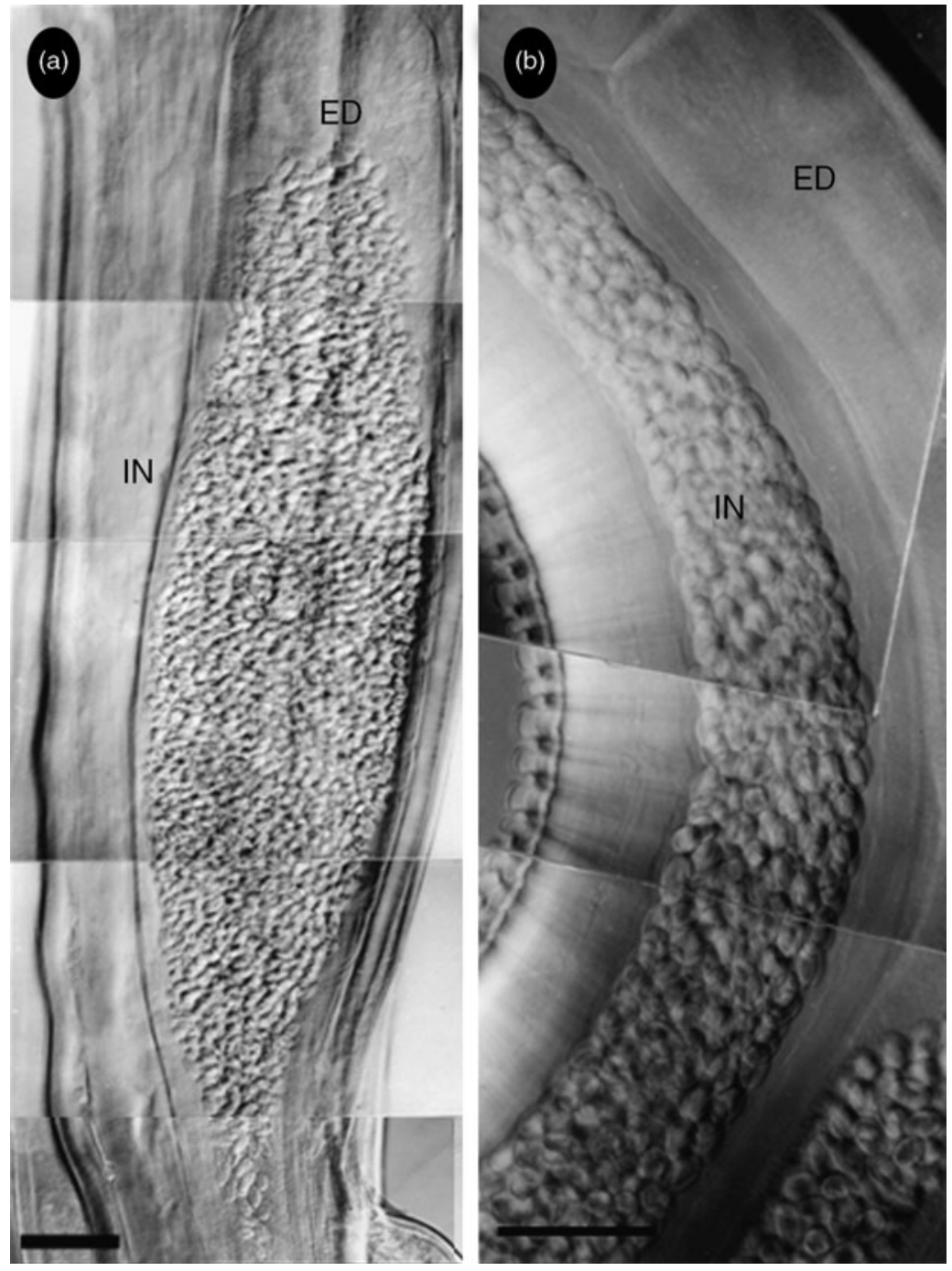

Fig. 2. Physaloptera bispiculata. Light microscopy of the male posterior region. Ejaculatory duct (ED) and intestine (IN) with uncountable eggs. Scale bars: (a) $100 \mu \mathrm{m}$; (b) $250 \mu \mathrm{m}$.

male during copulation probably pump and/or suck the eggs from the female uterus and vagina into the reproductive tubule and sometimes into the intestine of the male. The male probably does not have the ability to expel the eggs, and for this reason a large quantity were found in these organs. On the other hand, this could be an important adaptation for the parasite, i.e. when male worms are expelled by the host they can carry a large number of eggs and, if eaten by intermediate hosts, this allows the larvae to infect these new hosts.

As far as we know this is the first report of physalopterid nematode eggs harboured in the cloacal region, ejaculatory duct or intestine.

\section{Acknowledgements}

Brazilian financial support: Conselho Nacional de Desenvolvimento Científico e Tecnológico (CNPq),
Fundação Carlos Chagas Filho de Amparo a Pesquisa do Estado do Rio de Janeiro (FAPERJ) and Coordenação de Aperfeiçoamento de Pessoal de Nível Superior, CAPES-PROCAD.

\section{References}

Alden, K.J. (1995) Helminths of the opossum, Didelphis virginiana, in southern Illinois, with a compilation of all helminthes reported from this host in North America. Journal of the Helminthological Society of Washington 62, 197-208.

Blaxter, M.L., De Ley, P., Garey, J.R., Liu, L.X., Scheldeman, P., Vierstraete, A., Vanfleteren, J.R., Mackey, L.Y., Dorris, M. \& Frisse, L.M. (1998) A molecular evolutionary framework for the phylum Nematoda. Nature 392, 71-75. 
Gray, J.B. \& Anderson, R.C. (1982) Development of Turgida turgida (Rudolphi, 1819) in the common field cricket (Acheta pennsylvanica Burmeister). Canadian Journal of Zoology 60, 2134-2142.

Mafra, A.C. \& Lanfredi, R.M. (1998) Reevaluation of Physaloptera bispiculata (Nematoda: Spiruroidea) by light and scanning electron microscopy. Journal of Parasitology 84, 582-588.

Nettles, V.F., Prestwood, A.H. \& Davidson, W.R. (1975) Severe parasitism in an opossum. The Journal of Wildlife Diseases 11, 419-420.

Ortlepp, R. (1922) The nematode genus Physaloptera Rud. Proceedings of the Zoological Society of London 2, 999-1107.
Ortlepp, R. (1937) Some undescribed species of the nematode genus Physaloptera together with key to the sufficiently known forms. Onderstepoort Journal of Veterinary Science and Animal Industry 9, 71-84.

Stunkard, H.W. (1953) Life histories and systematics of parasitic worms. Systematic Zoology 2, 7-18.

Vaz, Z. \& Pereira, C. (1935) Some Brazilian nematodes. Transactions of the American Microscopical Society 54, 36-40.

Widmer, E.A. (1970) Development of third-stage Physaloptera larvae from Crotalus viridis Rafinesque, 1818 in cats with notes on pathology of the larvae in the reptile (Nematoda: Spiruroidea). The Journal of Wildlife Diseases 6, 89-93. 